\title{
Self-care behavior and related factors in older adults with hypertension in
} Ahvaz City

\author{
Barati F ${ }^{1}$, Sajjadi M², Farhadi A ${ }^{3}$, Amiri M ${ }^{4}$ *Sadeghmoghadam L ${ }^{5}$
}

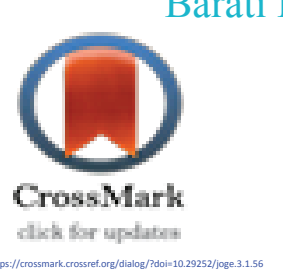

1- Student Research Committee, Nursing School, Gonabad University of Medical Sciences, Gonabad, Iran.

2- Associate Professor of Nursing Education,School of Nursing, Social Development and Health Promotion Research Center,Gonabad University of Medical Sciences, Iran.

3- Assistant Professor, Department of Nursing, School of Nursing and Midwifery, Bushehr University of Medical Sciences, Bushehr, Iran.

4- Assistant Professor, Department of Basic Sciences, School of Medicine, Gonabad University of Medical Sciences, Gonabad, Iran.

5- Assistant Professor, Department of Nursing, School of Nursing, ,Social Development and Health Promotion Research Center, Gonabad University of Medical Sciences, Gonabad, Iran (Correspondent Author)

E-mail: 1s_moghadam@yahoo.com

\section{Abstract}

Introduction: High blood pressure is the most important public health problem in developing countries. The implementation of self-care regarding its cost-effectiveness seems necessary. The aim of conducting this study was to investigate factors associated with self-care behaviors in elderly with hypertension.

Method: This cross-sectional study was carried out in 2017 on 300 elderly with hypertension who were under the treatment in community health centers in Ahvaz city. The data were collected through a demographic form and a self-care assessing instrument for hypertension. The collected data were put in the SPSS and analyzed using descriptive and inferential statistics t-test, Spearman and Pearson correlation and ANOVA tests at significant level of $\mathrm{P}<0.05$. based on hypertension selfcare and its relationship with demographic factors.

Results: Of 300 elderlies, $54 / 3 \%$ were woman that the most of them were married (80/7\%), with average economic status (59.7\%) and under diploma (73/66\%). The mean and standard deviation of total self care were 55/92 $\pm 8 / 94$. The results showed that there was a significantly positive relationship between self-care and hypertension history, income, and education level $(\mathrm{p}<0 / 05)$. However, there was no significant relationship between self-care and the variables of age, gender, and coincident disease $(\mathrm{p}>0 / 05)$.

Conclusion: Considering the importance of self-care in controlling hypertension and obtaining low self-care scores by the poorly literate elderly with low income, it is suggested that the age group be educated adequately through the extensive implementation of audio-visually educational programs.

Keywords: Self-care; Hypertension; Elderly.

Received: 6 August 2018

Accepted: 17 October 2018

\begin{tabular}{|l|l|}
\hline \multicolumn{3}{|c|}{ Access this article online } \\
\hline
\end{tabular}




\title{
رفتار هاى خودمراقبتى و عوامل مرتبط با آن در سالمندان مبتلا به يرفشارى خون شهر اهواز
}

\author{
فريده براتى'، موسى سجادى" ‘ اكرم فرهادى"، مصطفى اميرى"، "*ليا صادق مقدمه

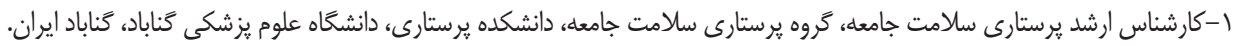

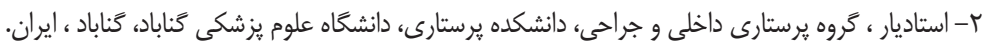

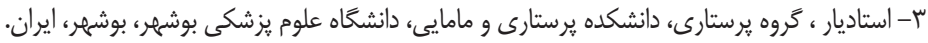

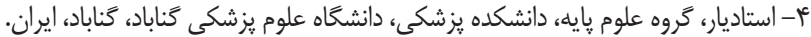

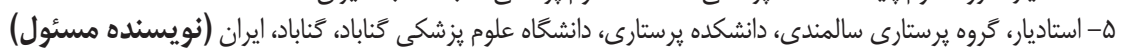 \\ يست الكترونيكى: 1s_moghadam@yahoo.com
}

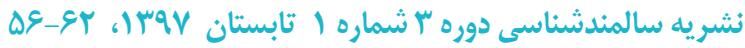

\section{جكيده}

مقدمه: يرفشارى خون به عنوان يكى از مشكلات مهم بهداشتى در كشورهاى در حال توسعه مطرح مى باشد، توجه بيشتر به

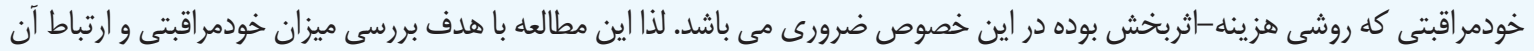
با عوامل مؤثر بر يرفشارى خون در سالمندان انجام كَرديد.

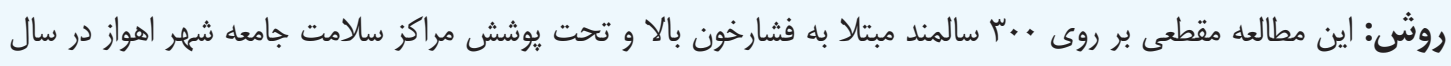
عوساصورت كرفت.اطلاعات توسط فرم اطلاعات دموكرافيك و ابزار سنجش خودمراقبتى يرفشارى خون جمع آورى شده و وارد نرم افزار SPSS

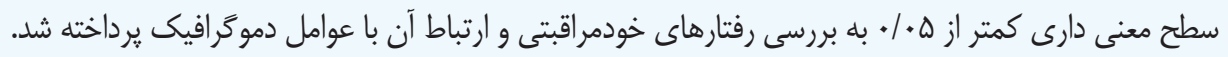

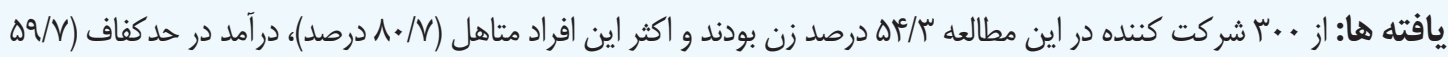

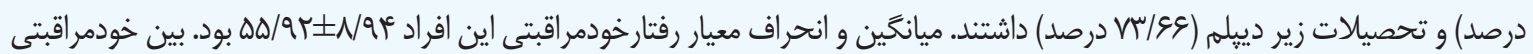

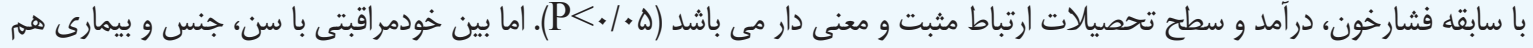

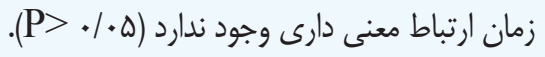

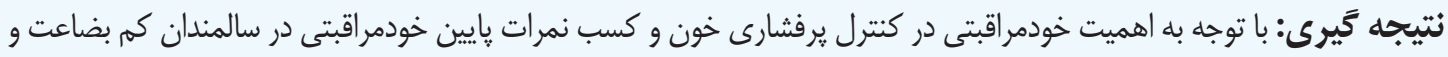

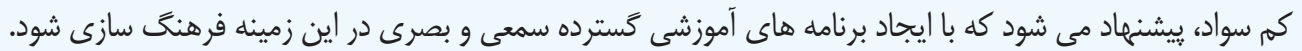
كليدوازه ها: خودمر اقبتى، يرفشارى خون، سالمند. 
شامل ارتقاى سلامت، اصلاح شيوه ى زندَّى، بيشخَيرى ازبيمارى،

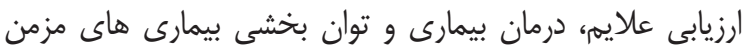

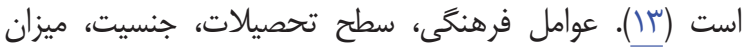
درآمد، سطح حمايت اجتماعى از سوى خانواده، دوستان و يا امكانات

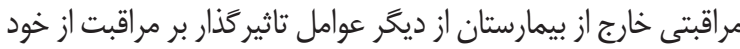

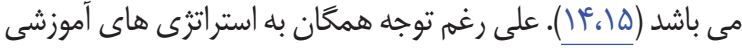

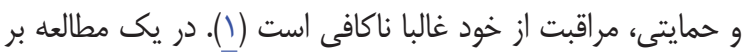
روى rی+r بيمار هم در كشورهاى در حال توسعه و هم توسعه يافته، حفظ و مديريت رفتارهاى مراقبت از خود در كليه ى نمونه ها ضعيف بود (1)). بر اساس نتايج تحقيقات و تجربيات به دست آمده در

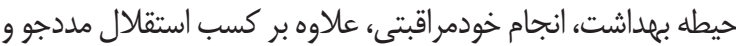
صرفه جويى اقتصادى، باعث كاهش اثرات بيمارى و ناتوانى و كاهش دوره بسترى در بيمارستان، نيز شده كه در نهايت به ارتقاء سطح سلامت در جامعه منجر خواهد شد، به عنوان موثرترين استراتثى براى بيشخيرى و كنترل بيمارى هاى مزمن به شمار مى رود (II).

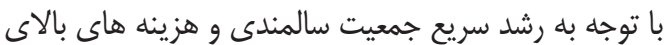
بيمارى هاى مزمن در اين گروه سنى و اهميت رفتارهاى خودمراقبتى در سالمندان مبتلا به برفشارى خون لازم است تا در جهت برن برنامها

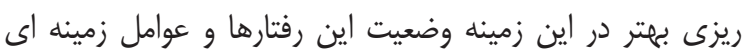

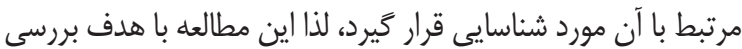
رفتارهاى خودمراقبتى و عوامل مرتبط با آن در سالمندان مبتلا به ير مفارى خون شهر اهواز انجام كرديد.

\section{ووش مطالعه}

يزوهش حاضر يك مطالعه مقطعى از نوع توصيفى تحليلى

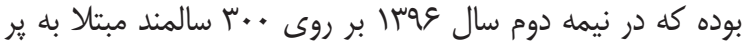
فشارى خون داراى يرونده بهداشتى در مراكز جامع سلامت شهر اهواز انجام كرفته است حجم نمونه مورد نياز براى انجام تحليل

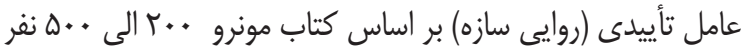
مى باشد كه در اين مطالعه .." نفر در نظر گرفته شد. نمونه كَيرى به صورت طبقه بندى خوشه ایى حندمرحله اى صورت كرفت به به نحوى كه مراكز بهداشت شرق و غرب اهواز به صورت طبقه و مراكز جامع خدمات سلامت شهرى به عنوان خوشه انتخاب كَ ديدند. از هر مركز بهداشت، " مر كز سلامت جامعه به روش تصادفى ساده انتخاب كرَديده و سيس از هر خوشه، كليه سالمندان تحت يوشش و مبتالا

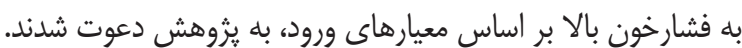
معيارهاى ورود به اين مطالعه شامل داشتن سن •ع سال و بالاتر، تكميل فرم رضايت نامه شركت در يزوهش، تاييد يزشك مبنى بر ابتلا به يرفشارى خون، دريافت داروهاى بإيين آورنده فشارخون و
مقامه

افزايش جمعيت سالمندان به قدرى قابل توجه است كه از آن

به عنوان انقاب ساكت ياد شده است. يِي بينى مى شود تا سال

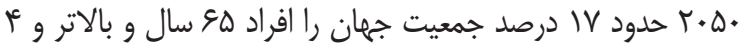

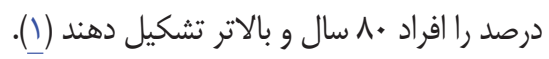

سالمندى يديده اى اجتناب نايذير بوده كه نتيجه آن، كاهش

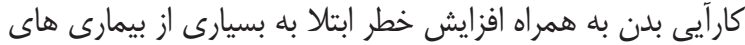

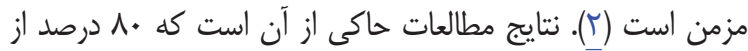
سالمندان حداقل به يكى از بيمارى هاى مزمن مبتلا هستند (ए).

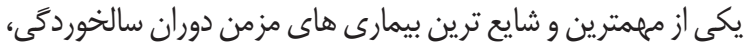

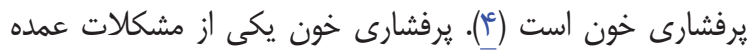
بهداشت عمومى در كليه كشورها بوده و تقريبا بادرصد ادرى آز آمار مركى و مير جهانى را به خود اختصاص داده است. شواهد نشان دهنده شيوع نسبتا بالاى اين بيمارى در ايران و جهان است (ه). اين بيمارى

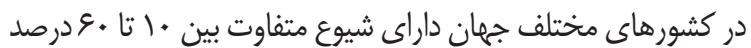
بوده و در ايران نيز، حدود • ب درصد از افراد به اين بيمارى مبتلا

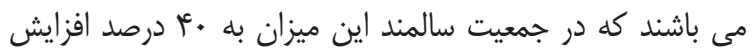

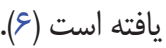

امروزه با ييشرفت تكنولوزى و ظهور فناورى هاى جديد، درمان هاى دارويى و غير دارويى متعددى براى يرفشارى وجود دارد اما على رغم سهولت درتشخيص و درمان، كتترل اين بيمارى هنوز يك حالش محسوب شده و هزينه هاى زيادى را بر سيستم هاى

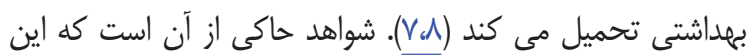

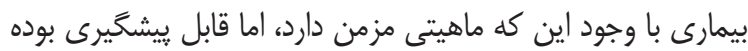
و مى توان با اصلاح شيوه زندگى، رعايت رزيم غذايى و بهبود رفتار

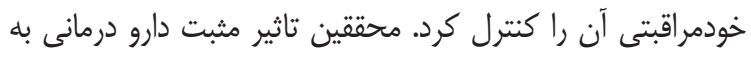
همراه استفاده از روش هايى مثل كاهش وزن، رعايت رزيم غذايى كم سديم، ترك مصرف دخانيات و داشتن فعاليت بدنى منظه را در كتترل فشارخون بالا به اثبات رسانده اند. نتايج آناليزهاى آمارى مطالعات بيشين، بيانكر كاهش ه و سَ/ ميلى متر جيوه در ميزان فشارخون سيستوليك و دياستوليك در نتيجه انجام خودمراقبتى بوده است (•(99). با توجه به اين كه يكى از اصول مهم در سياست هاى بهداشتى - درمانى، كاهش هزينه ها مى باشد، انتخاب روشى موثر و الهو

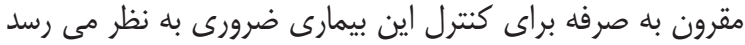

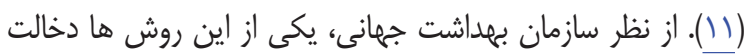

دادن بيمار در امر مراقبت از خود است (I) (I).).

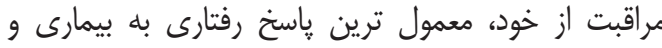
مهمترين شكل مراقبت هه در كشورهاى توسعه يافته و קه در كشورهاى درحال توسعه مى باشد و در بركيرنده فى فعاليت هايى 
در خصوص اهداف يزوهش توضيح كافى داده شد.

\section{كافْته ها}

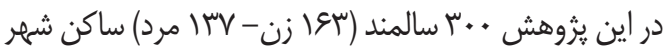

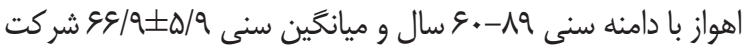

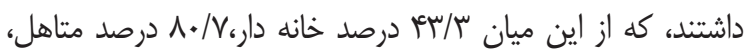

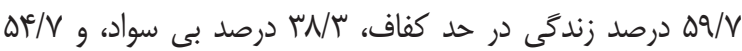
درصد زندگى با همسر و فرزندان را داشتند، ساير اطلاعات مربوط به توصيف متغيرهاى دموكرافيك در جدول شماره ا آورده شده است. ميانكين و انحراف معيار نمرات كسب شده رفتارهاى خودمراقبتى دورئى

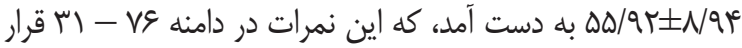
داشت (جدول (). يافته هاى آزمون تى مستقل نشان داد كه ميانگَين

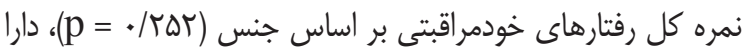
بودن يا نبودن بيمارى مزمن ديگر (p==/MV) تفاوت معنى دارى را نداشت (جدول ()). نتايج آزمون آناليز واريانس يكطرفه به اين صورت بود كه بين ميانگين هاى نمره كل خودمراقبتى در گروه هاى وضعيت

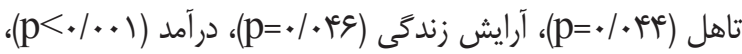

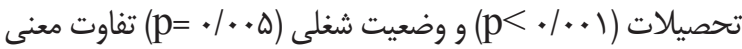
دار وجود دارد (جدول (). بالاترين ميانخين خودمراقبتى مربوط به

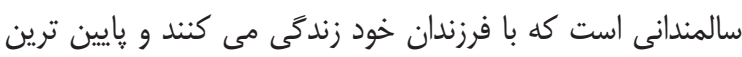
ميانكين مربوط به سالمندانى است كه با فاميل زندگى مى كى كنتد. آزمون تعقيبى توكى نشان داد در بين گروه تحصيلات تفاوت معات معنى

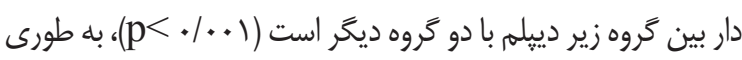

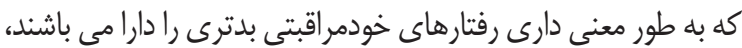

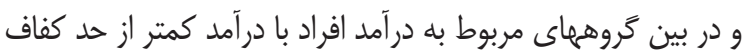

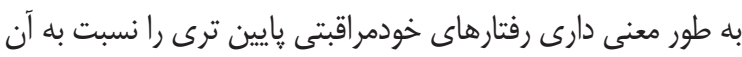

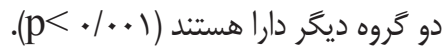
آزمون همبستخى يِيرسون نشان داد بين ميانگَين رفتارهاى

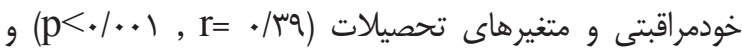

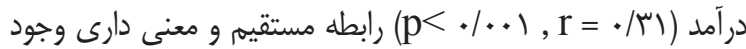
دارد، يعنى هر خه تحصيلات و درآمد بالاتر رود ميزان رفتارهاى خودمراقبتى بيشتر مى شود.

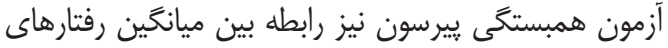
خودمراقبتى و سابقه فشار خون (سال هاى ابتلا) را مثبت و معنى دار

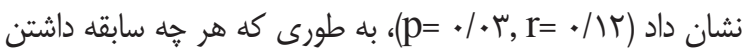
فشارخون بالاتر مى رود رفتارهاى خودمراقبتى بيشتر مى شود.
توانايى تكلم بله زبان فارسى بود.

ابزار جمع آورى داده ها شامل فرم جمع آورى اطلاعات بـات بود دموگرافيك (شامل سن، جنس، وضعيت اشتغال، وضعيت تاهل،

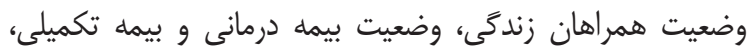

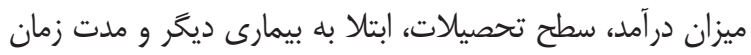
ابتلا به يرفشارى خون) و ير سشنامه خودمراقبتى يرفشارى خون ، كه

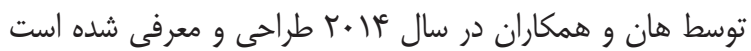

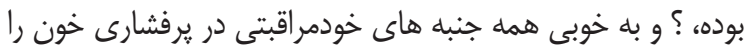

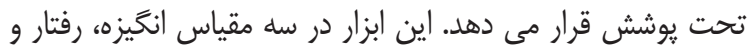

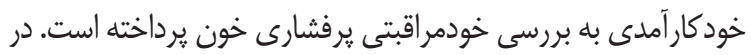

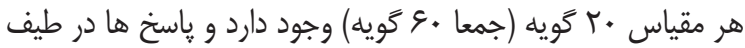

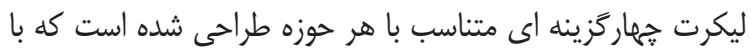

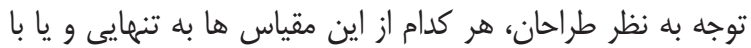
هم قابل استفاده هستند، و كسب نمره بالاتر به منزله خودمراقبتى بهتر است. در اين يروهش از مقياس رفتار اين ثرسشنامه كه حيطه

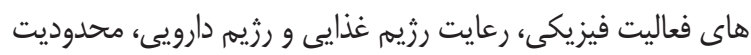
مصرف الكل و استعمال دخانيات، خوديايشى فشارخون، مديريت كنترل استرس و انجام ويزيت منظم توسط يزشك معالج را يوشش مصن مى دهد جهت بررسى خود مراقبتى سالمندان استفاده شد. پايايیى) همسانى درونى (ابعاد اين يرسشنامه بين سر/• تا سوح/ ت تعيين شده

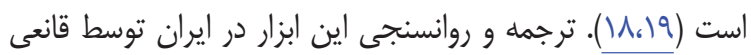

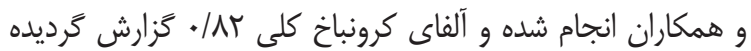

بعد از دادن توضيحات در خصوص نحوه تكميل تيرسشنامه ها در صورتى كه به هر دليلى (مشكلات بينايى، سطح تحصيلات و

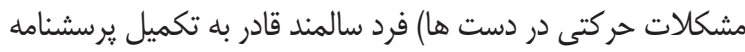

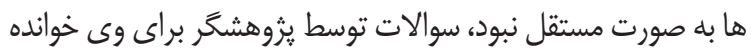
و تكميل شد.

در نهايت اطلاعات يرسشنامه وارد نرم افزار SpSS نسخه זَ كَرديده و با استفاده از آزمون هاى آمارى توصيفى (ميانخَين، انحراف معيار، فراوانى، درصد) و تحليلى (ضريب همبستخى يبيرسون

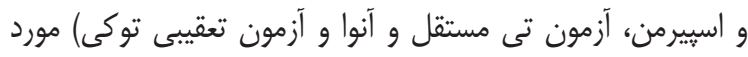
تجزيه و تحليل آمارى قرار گرفت، سطح معنى دارى در در اين مطالعه كمتر از هـ/• در نظر گرفته شد. نرمال بودن توزيع داده ها توسط آزمون آمارى كلمورَروف اسميرنوف مورد تاييد قرار گرفت. به منظور رعايت ملاحظات اخلاقى در اين مطالعه، قبل از شروع تحقيق مجوز انجام اين مطالعه از طريق كميته اخلاق دانشگًاه

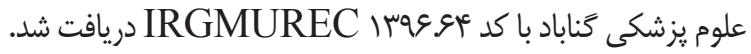
رضايت سالمندان جهت شركت در مطالعه مورد توجه قرار گرفت و 
جدول (: مقايسه وضعيت رفتارهاى خودمراقبتى بر اساس ويثگى هاى جمعيت شناختى در سالمندان شهر اهواز ( ...n r=)

\begin{tabular}{|c|c|c|c|c|c|}
\hline مقدار احتمال & 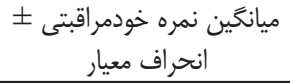 & درصد & تعداد & تقسيم بندى & متغير \\
\hline \multirow{3}{*}{. /TAT } & $\Delta \& / E V \pm N / \Delta T$ & $\Delta F / \Gamma$ & سوו & 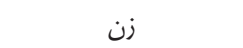 & جنسيت \\
\hline & $\Delta \Delta / r \Lambda \pm q / \leftarrow$. & $f \Delta / V$ & Irv & 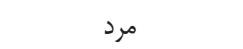 & \\
\hline & $\lceil\wedge / \cdot \Delta \pm \uparrow \mathcal{F} / \cdot \Delta$ & $11 / \mu$ & re & شاغل & \\
\hline \multirow[t]{4}{*}{ 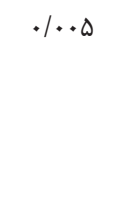 } & $\uparrow \wedge / \pi \mu \pm V / \notin \Delta$ & $\Delta / V$ & IV & بيكار & 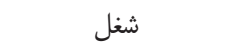 \\
\hline & $\Delta \cdot / \Delta V \pm V / \Delta r$ & r & r. & خانه دار & \\
\hline & $\Delta r / 11 \pm q / \Delta q$ & $\mathrm{rq} / \mathrm{v}$ & 119 & بازنشسته & \\
\hline & $\Delta F / V \Delta \pm I T / r \Lambda$ & $1 / r$ & r & مجرد & \\
\hline \multirow[t]{5}{*}{$\cdot \mid+\varphi^{\mathrm{c}}=$} & $\Delta \cdot / V T \pm N / q 1$ & $\Lambda \cdot / \vee$ & Tet & 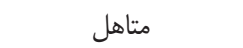 & وضعيت تاهل \\
\hline & $\Delta \mu / q V \pm \varepsilon / M$ & $\mid Q / \cdot$ & id & بيوه & \\
\hline & $F V / F q \pm \varepsilon / F q$ & 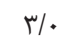 & 9 & مطلقه & \\
\hline & $\Delta \Gamma / \cdot 9 \pm N / \Delta T$ & $\mathrm{~V} / \cdot$ & M & تنها & \\
\hline & $\Delta / / 9 \Lambda \pm \Lambda / Q \Lambda$ & T/V & n & زندگى با همسر & \\
\hline \multirow[t]{4}{*}{$.1 \cdot+4 "$} & $\Delta \cdot / T \cdot \pm \Lambda / V V$ & $\Delta F / V$ & 194 & زندگى با همسر و فرزند & آرايش زندگى \\
\hline & $\Delta r / \Lambda r \pm \varepsilon / q q$ & $1 \% / \cdot$ & rq & زندگى با فرزند & \\
\hline & $r T / r \cdot \pm N / 9 q$ & $1 / V$ & $\Delta$ & زندگى با ساير بستخان & \\
\hline & $\Delta\rangle / \Delta \backslash \pm \Lambda / V V$ & $q \pi / r$ & ru. & دارد & \\
\hline \multirow[t]{2}{*}{$.1 \cdot 1^{* * *}$} & $\lceil \& / \Gamma \Delta \pm \Delta / \& \Lambda$ & $s / V$ & $r \cdot$ & 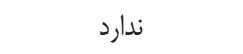 & بيمه يايه \\
\hline & $\Delta T / T I \pm q / T V$ & FN/V & lis & دارد & \\
\hline \multirow[t]{3}{*}{.$/ \cdot r^{\text {w*nkn}}$} & $\Delta \cdot / 19 \pm N / \cdot 1$ & $\Delta \backslash / \mu$ & IDF & 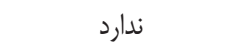 & بيمه تكميلى \\
\hline & $\Delta r / F \mid \pm N / q T$ & rq/. & $11 \mathrm{~V}$ & كمتر از حد نياز & \\
\hline & $\Delta \Lambda / \cdot \Lambda \pm \Lambda / r \Delta$ & $\Delta q / V$ & ivg & در حد نياز & \\
\hline \multirow[t]{2}{*}{$<\cdot|\cdot|^{*}$} & $\varepsilon / / \Delta \cdot \pm \varepsilon / V \Delta$ & $1 / r$ & r & بيشتر از حد نياز & وضعيت درآمد \\
\hline & $\Delta F / / H \pm N / r \Delta$ & $V \Psi / \& q$ & tri & زير دييلم & \\
\hline \multirow[t]{2}{*}{$<\cdot|\cdot \cdot|^{*}$} & $\Delta q / \vee \wedge \pm \wedge / q \uparrow$ & $1 N / r$ & $\Delta \Delta$ & دييلم & سطح تحصيلات \\
\hline & $\varepsilon N / \Delta \cdot \pm N / \Delta S$ & $\wedge$ & re & بالاى دييله & \\
\hline \multirow[t]{2}{*}{$\cdot / M A$} & $\Delta \Delta / 9 \vee \pm \Lambda / \mathcal{F}$ & $91 / \mu$ & $M F$ & دارد & بيمارى مزمن هم زمان \\
\hline & $\Delta \Delta / \wedge r \pm q / V V$ & rN/V & 118 & 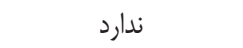 & \\
\hline
\end{tabular}

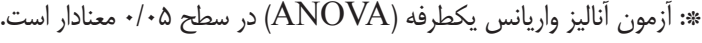

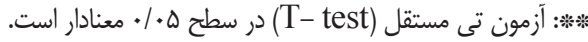

يافته هاى اين مطالعه نشان داده است كه بين سن و جنس

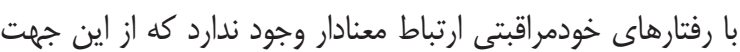
با مطالعات هزاوه اى و همكاران، آزادبخت و همكاران، يورمحمد و همكاران و سيدالشهدايى و همكاران همسو نمى باشد (·) (19، بr). مطالعه اقبالى و صالحى نشان داد كه بين خودمراقبتى با متغيرهايى خون سن، جنسيت و بيمارى همزمان ارتباط معنادار وجود ندارد كه به

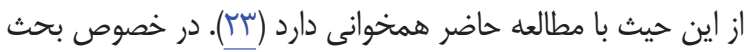
جنسيت ممكن است دليل اختلاف اين مطالعه با ساير مطالعات غير همسو به دليل وضعيت فرهنكى جوامعى كه نمونه گيرى در آنها

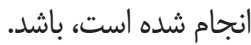
بر اساس يافته هاى تحقيق ارتباط آمارى معنادار بين رفتارهاى
اين يزوهش با هدف بررسى رفتارهاى خودمراقبتى و عوامل مرتبط با آن در سالمندان مبتلا به يرفشارى خون شهر اهواز بر انجام شد.

بيشترين سالمندان شركت كننده در اين يُوهش زن بودند. در مطالعه هزاوه اى و همكاران و محمد يور و همكاران نيز بيشترين سالمندان شركت كننده در يُوهش زن بودند (آيـــإ). كه با توجه به تصادفى بودن نمونه گَيرى، بيشتر بودن تعداد زنان سالمند يكى از

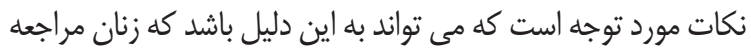
بيشترى به مراكز بهداشتى دارند و يا بيشتر از مردان ييخير برنامه هاى مراقبتى و آموزشى هستند. 
با خواندن سوالات براى سالمندان بى سواد اين مشكل را رفع نمايد.

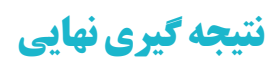

يافته ها حاكى از آن است كه رفتارهاى خود مراقبتى در

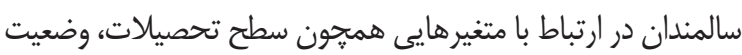

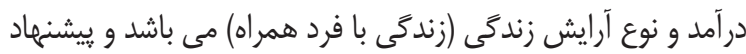
مى شود با ايجاد برنامه هاى آموزشى گسترده سمعى و بصرى در اين زمينه فرهنگ سازى صورت گيرد و به علاوه در جهت بهبود وضعيت اقتصادى و رفاهى سالمندان برنامه ريزى شود. و همهنين در مراكز

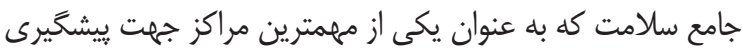
و كنترل بيمارى هاى مزمن غيرواگير شناخته ميشوند مى توان برنامه ريزى دقيق ترى را در جهت كنترل رفتارهاى خودمراقبتى در سالمندان مبتلا به يرفشارى خون بر اساس عوامل دموَّرافيك موثر بر اين رفتارها انجام داد.

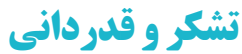

اين مقاله برگرفته از קايان نامه كارشناسى ارشد يرستارى

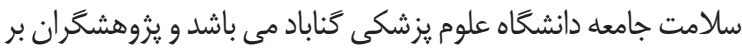
خود لازم مى دانند از همكارى صميمانه اعضاء هيئت علمى دانشگاه

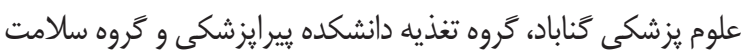

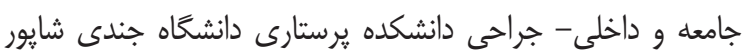
اهواز و همجنين مراقبين سلامت و سالمندان شركت كننده در اين يخوهش تقدير و تشكر نمايند.

\section{References}

1. Aghajani S, Samadifard HR .The Role of Cognitive Fusion, Locus of Control and Cognitive Avoidance in the Prediction of Death Anxiety in the Elderly. 2017.

2. Jamshidi L SA. Comparison of cardiovascular diseases risk factors in male and female older adults of Hamadan City, 2014. Journal of Gerontology (joge). 2016; 1 (1):1- 10.

3. Peyman H YM, Seyed Mohammadi A, Delpishe A. Evaluation of Prevalence of Chronic Disease in Older Adults in Elam. SALMAND. 2011; 6 (22):7- 13 .

4. Abdollahzadeh R MR. Investigating the condition of the elderly in Sarbisheh, Southern Khorasan State. Nursing Journal of the Vulnerable. 2017; 3 (9):14- 23.

5. Park JB, Kario K, Wang J-G. Systolic hypertension: an increasing clinical challenge in Asia. Hypertension Research. 2015; 38 (4):227.
خودمراقبتى با سطح درآمد بدست آمد كه با مطالعه براتى و همكاران، مظلومى و همكاران، آزادبخت و همكاران و يورمحمد و همكاران

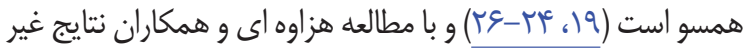
همسو دارد (VI) (19). در توجيه اين نتيجه مى توان اين طور بيان نمود كه وضعيت مناسب اقتصادى، باعث افزايش دسترسى سالمندان به خدمات بهداشتى، درمانى و دريافت خدمات رفاهى بيشتر و در نتيجه افزايش توان خودمراقبتى خواهد شد. يثرهش حاضر بيانگر آن است كه بين رفتارهاى خودمراقبتى

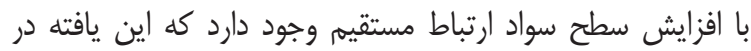
مطالعه آزادبخت و همكاران، براتى و همكاران و مظلومى و همكاران

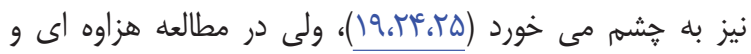
همكاران جنين رابطه اى بدست نيامد (+(). بنظر مى رسد افراد داراى سطوح بالاتر تحصيلى با برخوردارى از امكان برقرارى ارتباط بهتر با

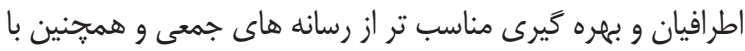
امكان دستيابى به موقعيت هاى اقتصادى و اجتماعى بهتر، مى توانند راه هاى مناسب ترى براى مراقبت از خود يبدا كنند. اين مطالعه همجون ساير مطالعات داراى محدوديت هايى است از جمله اينكه تعداد بيشتر زنان نسبت به مردان بود، كه براى مشاركت مردان سالمند نياز به برنامه ريزى بيشترى مى بـ باشد.

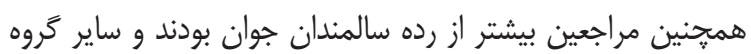

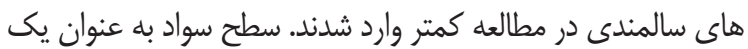
عامل تأثير گذار در تكميل يرسشنامه ها بود كه يثوهشگر سعى نمود

6. Khezeli M. Study on the prevalence of hypertension and its associated factors in the elderly population. La Revue du praticien. 2012; 62 (9): 1225-8.

7. Neminqani DM E-SE, Thubiany MMA. Hypertensive Patients: Self-Care Management Practices in Al-Taif, KSA. International Journal of Science and Research. 2015; 4 (12): 1705-14.

8. Woolf KJ, Bisognano JD. Nondrug interventions for treatment of hypertension. The Journal of Clinical Hypertension. 2011; 13 (11): 829-35.

9. Gupta S, Geeta K, Mehto G. Self-Care Behaviour Practices and Related Factors among Hypertensive Men and Women in Delhi. Asian Journal of Multidisciplinary Studies. 2016; 4 (1).

10. Hazavehei S, Dashti S, Moeini B, Faradmal J, Shahrabadi R, Yazdi A. Factors related to selfcare behaviors in hypertensive individuals based on Health Belief Model. Koomesh. 2015; 17 (1): $37-44$. 
11. Mohammdi MA DB, Sezawar SH, Mozafari N. Tracking the effect on blood pressure control in patients with hypertension. Journal of Ardabil University of Medical Sciences. 2006; 6 (2):15662.

12. Motlagh SFZ, Chaman R, Sadeghi E, Eslami AA. Self-care behaviors and related factors in hypertensive patients. Iranian Red Crescent Medical Journal. 2016;18 (6).

13. Nolte E, McKee M. Caring for people with chronic conditions: a health system perspective: McGraw-Hill Education (UK); 2008.

14. Kato N, Kinugawa K, Ito N, Yao A, Watanabe M, Imai Y, et al. Adherence to self-care behavior and factors related to this behavior among patients with heart failure in Japan. Heart \& Lung: The Journal of Acute and Critical Care. 2009; 38 (5): 398-409.

15. Lainščak M, Cleland JG, Lenzen MJ, Keber I, Goode K, Follath F, et al. Nonpharmacologic measures and drug compliance in patients with heart failure: data from the EuroHeart Failure Survey. The American journal of cardiology. 2007; 99 (6):S31-S7.

16. Riegel B, Moser DK, Anker SD, Appel LJ, Dunbar SB, Grady KL, et al. State of the science. Promoting self-care in persons with heart failure. A scientific statement from the American Heart Association. Circulation. 2009.

17. Hemmati Maslak Pak M, Hashemlo L. Design and Psychometric Properties of a Self-Care Questionnaire for the Elderly. Iranian Journal of Ageing. 2015;10 (3):120-31.

18. Han H-R, Lee H, Commodore-Mensah Y, Kim M. Development and validation of the hypertension self-care profile: a practical tool to measure hypertension self-care. The Journal of cardiovascular nursing. 2014; 29 (3): E11.

19. Azadbakht M, Garmaroodi G, Taheri Tanjani P, Sahaf R, Shojaeizade D, Gheisvandi E. Health promoting self-care behaviors and its related factors in elderly: application of health belief model. J Educ Community Health. 2014;1 (2): 20-9.

20. Gheshlagh RG, Parizad N, Ghalenoee M, Dalvand S, Baghi V, Najafi F, et al. Psychometric Features of the Persian Version of Self-Efficacy Tool for Patients with Hypertension. International Cardiovascular Research Journal. 2018;12 (2).
21. Mohammadpour A, Sadeghmoghadam L, Shareinia H, Jahani S, Amiri F. Investigating the role of perception of aging and associated factors in death anxiety among the elderly. Clinical interventions in aging. 2018; 13:405.

22. Seyedoshohadaee M, Barasteh S, Jalalinia F, Eghbali M, Nezami M. The relationship between health literacy and self-care behaviors in patients with type 2 diabetes. Iranian Journal of Nursing Research. 2016; 10 (4):43-51.

23. Eghbali T SS. The Effect of Nursing Intervention Education on Self-care Behaviors in Patients with High Blood Pressure Referred to Healthcare Centers in Kermanshah Province Iranian Journal of Rehabilitation Research in Nursing (IJRN). 2017;4 (1).

24. Barati M, Darabi D, Moghimbeigi A, Afsar A. Self-regulation behaviors of hypertension and related factors among hypertensive patients. Journal of Fasa University of Medical Sciences. 2011;1 (3):116-22.

25. Mazloomy S, Mirzaei A, Afkhami Ardakani M, Baghiani Moghadam M, Fallahzadeh H. The role of health beliefs in preventive behaviors of individuals at high-risk of type2 diabetes mellitus. SSU_Journals. 2010;18 (1):24-31.

26. JZ PS. Related factors to self-care behaviors in elderly with hypertension based on the Health Belief Model in Uremia County. Journal of Gerontology (joge). 2017; 2 (1):41-50.

27. Poormuhamad S JZ. Related factors to self-care behaviors in elderly with hypertension based on the Health Belief Model in Uremia County Journal of Gerontology (joge). 2017; 2 (1):41-50. 